\title{
Approximate multi-Jensen and multi-quadratic mappings in 2-Banach spaces
}

\section{KRZYSZTOF CIEPLIŃSKI and TIAN ZHOU XU}

\begin{abstract}
.
In this paper we prove the generalized Hyers-Ulam stability of multi-Jensen and multi-quadratic mappings in 2-Banach spaces. The corollaries from our main results correct some outcomes from [Park, W.-G., Approximate additive mappings in 2-Banach spaces and related topics, J. Math. Anal. Appl., 376 (2011) 193-202].
\end{abstract}

Acknowledgement. The second author was supported by the National Natural Science Foundation of China (11171022).

\section{REFERENCES}

[1] Agarwal, R. P., Xu, B. and Zhang, W., Stability of functional equations in single variable, J. Math. Anal. Appl., 288 (2003), 852-869

[2] Aoki, T., On the stability of the linear transformation in Banach spaces, J. Math. Soc. Japan, 2 (1950), 64-66

[3] Bourgin, D. G., Classes of transformations and bordering transformations, Bull. Amer. Math. Soc., 57 (1951), 223-237

[4] Cădariu, L. and Radu, V., A general fixed point method for the stability of the monomial functional equation, Carpathian J. Math., 28 (2012), 25-36

[5] Ciepliński, K., On multi-Jensen functions and Jensen difference, Bull. Korean Math. Soc., 45 (2008), 729-737

[6] Ciepliński, K., Stability of the multi-Jensen equation, J. Math. Anal. Appl., 363 (2010), 249-254

[7] Ciepliński, K., On the generalized Hyers-Ulam stability of multi-quadratic mappings, Comput. Math. Appl., 62 (2011), 3418-3426

[8] Ciepliński, K., Stability of multi-Jensen mappings in non-Archimedean normed spaces, in Functional Equations in Mathematical Analysis, Springer, New York, 2012, 79-86

[9] Freese, R. W. and Cho, Y. J., Geometry of linear 2-normed spaces, Nova Science Publishers, Inc., Hauppauge, NY, 2001

[10] Găvrută, P., A generalization of the Hyers-Ulam-Rassias stability of approximately additive mappings, J. Math. Anal. Appl., 184 (1994), 431-436

[11] Hyers, D. H., On the stability of the linear functional equation, Proc. Nat. Acad. Sci. U. S. A., 27 (1941), 222-224

[12] Jung, S.-M., Hyers-Ulam-Rassias Stability of Functional Equations in Nonlinear Analysis, Springer, New York, 2011

[13] Park, W.-G., Approximate additive mappings in 2-Banach spaces and related topics, J. Math. Anal. Appl., 376 (2011), 193-202

[14] Popa, V., Stability of some functional equations defined by quasiarithmetic means, Carpathian J. Math., 28 (2012), $151-156$

[15] Prager, W. and Schwaiger, J., Multi-affine and multi-Jensen functions and their connection with generalized polynomials, Aequationes Math., 69 (2005), 41-57

[16] Prager, W. and Schwaiger, J., Stability of the multi-Jensen equation, Bull. Korean Math. Soc., 45 (2008), 133-142

[17] Rassias, Th. M., On the stability of the linear mapping in Banach spaces, Proc. Amer. Math. Soc., 72 (1978), 297-300

[18] Rus, I. A., Ulam stabilities of ordinary differential equations in a Banach space, Carpathian J. Math., 26 (2010), 103-107

Received: 30.04.2012; In revised form: 03.10.2012; Accepted: 12.12.2012

2010 Mathematics Subject Classification. 39B82.

Key words and phrases. Stability, multi-Jensen mapping, multi-quadratic mapping, linear 2-normed space.

Corresponding author: Krzysztof Ciepliński; kc@up.krakow.pl 
[19] Xu, T. Z., On the stability of multi-Jensen mappings in $\beta$-normed spaces, Appl. Math. Lett., 25 (2012), 1866-1870

[20] Xu, T. Z. Stability of multi-Jensen mappings in non-Archimedean normed spaces, J. Math. Phys., 53 (2012), 023507, $9 \mathrm{pp}$

Pedagogical University

INSTITUTE OF MATHEMATICS

PODCHORA̧ŻYCH 2, 30-084, KRAKÓW, POLAND

E-mail address: kc@up.krakow.pl

BEIJING INSTITUTE OF TECHNOLOGY

SCHOOL OF MATHEMATICS

100081, BEIJING, P.R. CHINA

E-mail address: xutianzhou@bit.edu.cn 